\title{
Análise de informações sobre sustentabilidade ambiental circulantesno Orkut: estudo exploratório do tópico "E o rio?"
}

Júlia Gonçalves da Silveira

\begin{abstract}
Doutora em Ciência da Informação. Professora Adjunta da Escola de Ciência da Informação da UFMG
\end{abstract}

\section{Ruleandson do Carmo Cruz}

\section{Mestre em Ciência da Informação}

Apresenta resultados de um estudo exploratório do tópico "E o rio?", criado na comunidade virtual "Ferros MG" existente no Orkut. Nele, os diversos membros debatem sobre a instalação de pequenas centrais hidrelétricas na bacia do Rio Santo Antônio, que banha a cidade mineira de Ferros. Revela facetas do comportamento informacional dos debatedores do citado tópico, em momentos de busca e de troca de informações de interesses coletivos. Conclui que as informações prevalecentes nas discussões clamam por maior transparência de informações por parte das autoridades municipais e estaduais em assuntos que afetem a comunidade local, entre outras constatações apresentadas.

Palavras-chave: Orkut; Redes sociais virtuais; Comunidades virtuais; Comportamento de usuários; Sustentabilidade ambiental; Informação ambiental; Rios; Cidades - meio ambiente; Ferros - MG; Comportamento Informacional; Bacias Hidrelétricas. 


\title{
Study of information about environmental sustainability that circulate on Orkut: an exploratory study of the topic "What about the river?" ("E o rio?)
}

\begin{abstract}
It presents the results of an exploratory study of the topic: "What about the river?" ("E o rio?"), created at the virtual community "Ferros MG", existing at Orkut. At the topic, the members debate the installation of smalls hydroelectric centrals at Santo Antônio river basin, which covers the city of Ferros. It also reveals facets of the mentioned topic debaters during moments of searching and exchanging of collective interest information. Finally, it concludes that the prevailing information in the discussions clame for more information transparence from municipal and state authorities in issues that affect the local community, besides other presented findings.
\end{abstract}

Keywords: Orkut; Social network; Virtual communities; User behavior; Environmental sustainability; Environmental information; Rivers; City - environment; Ferros/MG; Informational behavior; Hydroelectric basins.

Recebido em 14.10.2010 Aceito em 15.05.2012

\section{Introdução}

Comunicar, informar e buscar novos conhecimentos constituem ações corriqueiras e naturais executadas pela humanidade ao longo de sua existência.

Marteleto (1998, p. 78) observa que "tanto o senso comum quanto o pensamento científico" associam a informação ao conhecimento e à comunicação, o que denota a existência de uma articulação, quase automática, entre os três termos.

Comunicação, informação e conhecimento são fenômenos sociais dinâmicos e interativos materializados nas práticas, nas representações e nas relações sociais estabelecidas entre sujeitos coletivos.

Macedo (1999, p. 94) esclarece:

Os fluxos de informação nas sociedades em geral e nas organizações orientam-se naturalmente no sentido de maior atendimento às necessidades de informação dos seus usuários, atravessando aquelas estruturas e iluminando as 
questões que dizem respeito às relações entre a organização formal e suas dinâmicas informais de comunicação.

Essa autora, entre outros pesquisadores que estudam a mesma temática, considera que redes humanas são centrais para disseminar informações e suprir necessidades de informação, sendo o contato interpessoal o meio mais ágil e eficiente de se buscar e acessar informações.

Com o advento e democratização da Internet, a partir de meados da década de 90, surgiram novas modalidades de comunicação e novos espaços de troca, de compartilhamento de informações, de criação e geração de novos conhecimentos. Destaca-se, nesse contexto, a formação das redes sociais virtuais, nas quais pessoas discutem assuntos de interesses afins, trocam mensagens, divulgam conteúdos diversos através de blogs, transmitem sons e imagens, entre outras possibilidades e modalidades de compartilhamento de ideias, de ideais e inquietações.

Entre inquietações que afetam a sociedade mundial contemporânea ressalta-se aquela direcionada às consequências da degradação do meio ambiente. É o que se observa em manifestações amplamente divulgadas nos mais diversos canais de circulação de informações nacionais e internacionais.

A humanidade discute temas preocupantes como aquecimento global, uso consciente da água, entre outros, colocando a sustentabilidade ambiental como preocupação global. Por outro lado, vivemos em uma sociedade em que "a economia capitalista exige um nível e tipo de produção e consumo que são ambientalmente insustentáveis". (JACOBI, $2006^{1}$, resenhando livro de PORTILHO, 2005).

Entende-se a sustentabilidade ambiental como "necessidade do planejamento racional na busca [...] da manutenção dos recursos naturais em escala planetária", conforme pondera Maglio (2005, p. 14), o qual ainda esclarece que esta discussão foi fortalecida pela Conferência Mundial Sobre o Meio Ambiente e o Desenvolvimento, mais conhecida como Rio 92 ou Eco 92.

Este artigo apresenta resultados de um estudo exploratório do fluxo e uso de informações registradas no tópico "E o rio?"2, relacionadas à sustentabilidade ambiental e informação ambiental, postadas por integrantes da comunidade virtual "Ferros $\mathrm{MG}^{3}$ ", presente no site Orkut. Neste tópico, alguns membros da citada comunidade discutem acerca do processo de instalação de pequenas centrais hidrelétricas ( $\mathrm{PCHs}$ ) na bacia do Rio Santo Antônio, que banha todo o município de Ferros e alguns de seus distritos.

\footnotetext{
${ }^{1}$ Disponível em: <http://www.scielo.br/scielo.php?pid=S1414-753X2006000100010\&script=sci arttext>. Acesso em: 20 jul. 2011.

${ }^{2}$ Disponível em:

<http://www.orkut.com.br/Main \#CommMsgs.aspx?cmm=78051\&tid=2496048620922952704 >. Acesso em: 20 jul. 2011.

${ }^{3}$ Disponível em: <http://www.orkut.com.br/Main\#Community?cmm=78051>. Acesso em: 20 jul. 2011.
} 
Sob esta perspectiva, pretendeu-se identificar, através das informações circuladas nessa rede social virtual, composta por parte da população ferrense, como a cidade estaria reagindo diante dos impactos ambientais decorrentes da instalação das referidas PCHs. Acreditava-se que, através da análise das informações registradas no tópico em estudo, poder-se-ia, também, identificar o comportamento informacional das pessoas que discutiam sobre o assunto.

A importância dos estudos de usuários e de uso da informação, incluindo abordagens sobre o comportamento informacional destes, compreendida como a maneira pela qual os indivíduos lidam com a informação, incluindo "a busca, o uso, a alteração, a troca, o acúmulo, até mesmo o ato de ignorar os informes" (DAVENPORT, 2000) vê-se mencionada na literatura nacional e internacional, o que justifica o presente estudo sob a ótica da ciência da informação.

Assim, esta pesquisa mostrará tipos de informações que circulam entre os membros da comunidade virtual "Ferros MG", no tópico "E o rio?", que discute sobre sustentabilidade ambiental. Autores como Gonzalez de Gomez (1990) destacam a importância de estudos dessa natureza para a ciência da informação, que deve considerar os setores da sociedade civil e suas expressões organizadas, enquanto objetos de pesquisas acadêmicas.

Perceber, portanto, se havia conscientização política em relação aos impactos ambientais e de outras naturezas ou implicações sociais, que poderiam afetar diretamente aquela comunidade, assim como avaliar sua manifestação pública no Orkut, da mesma forma, também constituíram objetivos desta pesquisa.

\section{Sobre o Orkut}

O Orkut se autodefine ${ }^{4}$ como uma comunidade online de acesso gratuito, criada para tornar a vida social de seus membros mais ativa e estimulante, por meio da troca de fotos e mensagens entre amigos e da possibilidade de conhecer novas pessoas. Através do Orkut, os usuários podem interagir com membros que possuam os mesmos interesses e ideias ao participar, via adesão às redes virtuais de relacionamento, das denominadas comunidades virtuais, que agrupam pessoas que se identificam com os temas propostos por elas.

O Orkut, comunidade online, comparada com outras ferramentas sociais, (blogs, MSN, fotolog, IRC) tem papel importante no processo de alfabetização digital. Considerada a de maior adesão pelos brasileiros, conforme Recuero (2009) ${ }^{5}$, foi lançada na Internet em 24 de janeiro de $2004^{6}$, sendo seu criador o engenheiro de software Orkut Buyukkokten.

Segundo informações fornecidas por Assessoria Google (2008), em Dados sobre o Orkut, o site já possuía, nessa ocasião, mais de sessenta

\footnotetext{
${ }^{4}$ Disponível em: <http://www.orkut.com.br/About.aspx>. Acesso em: 10 jul. 2010.

${ }^{5}$ Disponível em: <http://pontomidia.com.br/raquel/arquivos/futures_of_learning_o_orkut_e_o_brasil.html>. Acesso em: 10 jul. 2010.

${ }^{6}$ Disponível em: <http://blog.orkut.com/2009/01/orkut-is-turning-five.html>. Acesso em: 10 jul. 2010.
} 
milhões de usuários, sendo que destes aproximadamente trinta milhões eram brasileiros.

Conforme informações divulgadas pelo IBOPE $^{7}$, em relatório de pesquisa de audiência datado de 09 de setembro de 2011, o acesso à Internet, ocorrido em certos ambientes brasileiros incluindo domicílios, locais de trabalho, escolas e lan houses, atingiu 77,8 milhões de pessoas no segundo trimestre de 2011 , sendo esse número $5,5 \%$ superior ao do segundo trimestre de 2010 e $20 \%$ maior que o do segundo trimestre de 2009, o que reflete crescimento acentuado de seus usuários. Observou-se que houve maior crescimento de acesso em residências, onde $87 \%$ dos internautas utilizam sites sociais, sendo os de maior alcance o Facebook (30,9 milhões de usuários), o Orkut (29 milhões de usuários) e o Twitter (14,2 milhões de usuários).

Esses dados foram contestados por Fraga (2011), em documento eletrônico disponível em: http://googlediscovery.com/2011/09/15/comscore-orkutlidera-as-redes-sociais-no-brasil/, argumentando que a "ComScore, empresa de pesquisas de maior credibilidade no mundo" aponta que o Orkut ainda é a maior rede social do país, embora reconheça que "o Facebook vem crescendo a passos largos, reduzindo em 20\% a diferença entre os sites", considerando resultados de pesquisas referentes aos meses de julho e agosto de 2011.

\subsection{Acesso dos usuários brasileiros ao Orkut}

No que se refere ao acesso do brasileiro ao Orkut, uma pesquisa sobre o comportamento de usuários da Internet no país, realizada em 2007 pelo Ibope, indicava que o brasileiro passava, em média, três vezes mais tempo conectado ao Orkut (cinco horas mensais) do que ao próprio serviço de e-mail (uma hora e 40 minutos) ${ }^{8}$. Além disso, o Instituto indicava: o Orkut é o site mais acessado no Brasil, ficando à frente até mesmo da famosa ferramenta de busca Google ${ }^{9}$.

Resultados de pesquisas posteriores, divulgadas pelo IBOPE Nielsen Online, em novembro de 2011, indicam que, em média, cada usuário brasileiro de redes sociais conectou-se a esses sites de relacionamento por um tempo de 7 horas e 14 minutos mensais, o que mostra que eles ocupam posição de destaque entre preferências de locais de acesso à Internet, considerando os demais recursos de informação e comunicação disponibilizados pela rede de redes. ${ }^{10}$.

Diante dessa comprovada popularização do Orkut no país, parece haver certo preconceito no sentido de que esse site de relacionamento

\footnotetext{
${ }^{7}$ Disponível em:

http://www.ibope.com.br/calandraWeb/servlet/CalandraRedirect?temp $=6 \& p r o j=$ PortalIBOPE\&pub $=T \& d b=c a l d b$ \&comp = pesquisa leitura\&nivel=null\&docid=C2A2CAE41B62E75E83257907000EC04F Acesso em: 06 out. 2011.

${ }^{8}$ Disponível em: <http://www1.folha.uol.com.br/folha/informatica/ult124u356362.shtml>. Acesso em: 10 jul. 2010 .

${ }^{9}$ Disponível em: <http://br.tecnologia.yahoo.com/article/30012008/25/tecnologia-noticias-site-acessadobrasil-sinais-queda.html>. Acesso em: 10 jul. 2010.

${ }^{10}$ Disponível em:

$<$ http://www.ibope.com.br/calandraWeb/servlet/CalandraRedirect?temp=6\&proj=PortalIBOPE\&pub $=$ T\&nome $=$ h ome materia\&db=caldb\&docid=C2A2CAE41B62E75E83257907000EC04F> Acesso em: 06 mar. 2012.
} 
social esteja sendo utilizado somente para circulação de banalidades e discussões irrelevantes. Sob outra ótica, entre a troca de mensagens cotidianas, incluindo recados e fotos, percebem-se lacunas de pesquisas científicas que avaliem informações circuladas em comunidades virtuais que discutem temas inegavelmente relevantes, entre eles "ecologia", "sustentabilidade", "sustentabilidade ambiental", "aquecimento global", citando os estritamente relacionados com o presente trabalho.

\section{Redes sociais, redes sociais virtuais e comunidades virtuais}

Para Recuero (2009) ${ }^{11}$ a rede social é formada por "um grupo de pessoas, compreendido através de uma metáfora de estrutura, a estrutura de rede. Os nós da rede representam cada indivíduo e suas conexões."

Quanto às redes sociais na Internet ela assim as compreende:

Redes sociais na Internet são constituídas de representações dos atores sociais e de suas conexões. Essas representações são, geralmente, individualizadas e personalizadas. Podem ser constituídas, por exemplo, de um perfil no Orkut, um weblog ou mesmo um fotolog. As conexões, por outro lado, são os elementos que vão criar a estrutura na qual as representações formam as redes sociais. Essas conexões, na mediação da Internet, podem ser de tipos variados, construídas pelos atores através da interação, mas mantidas pelos sistemas online. Por conta disso, essas redes são estruturas diferenciadas. Ora, é apenas por conta desta mediação específica que é possível a um ator ter, por exemplo, centenas ou, até mesmo, milhares de conexões, que são mantidas apenas com o auxílio das ferramentas técnicas. Assim, redes sociais na Internet podem ser muito maiores e mais amplas que as redes offline, com um potencial de informação que está presente nessas conexões.

Assim, a autora observa que a Internet é responsável por ampliar em larga escala as possibilidades de conexões e de difusão de informações das redes sociais.

Outros autores, destacando Marteleto e Silva $(2004)^{12}$, reforçam a grande contribuição da análise de redes sociais para compreensão do papel do capital social no desenvolvimento das comunidades e da inclusão social destas. Para estes autores citados, capital social pode ser entendido como "as normas, valores, instituições e relacionamentos compartilhados que permitem a cooperação dentro ou entre os diferentes grupos sociais." (p. 44).

\footnotetext{
${ }^{11}$ Disponível em: < http://books.google.com.br/books?id=w3B-psPtggEC\&pg=PA23\&hl=pt$B R \&$ source $=g b s$ toc $r \& c a d=4 \# v=$ onepage\&q\&f=false $>$. Acesso em: 10 jul. 2010.

12 Disponível em: <http://revista.ibict.br/ciinf/index.php/ciinf/article/view/518/472> . Acesso em: 06 out. 2011.
} 
No mundo contemporâneo, com o advento e democratização da Internet, as redes sociais ultrapassaram o âmbito acadêmico/científico, conquistando e ganhando espaço em outras esferas sociais (TOMAÉL et al., 2005, p. 95).

Observa-se que esse movimento chegando à Internet conquista cada vez mais adeptos, aglutinando pessoas com objetivos específicos, ou apenas pelo prazer de trazer à tona ou desenvolver uma rede de relacionamentos.

Garton; Haythornthwaite; Wellman (1997) observam que uma rede social virtual constitui-se quando um computador conecta pessoas ou organizações ou outras entidades sociais.

Transpondo a metáfora de rede, usada para entender uma estrutura social para o ambiente online, Recuero (2009, p. 25) define rede social virtual como a "teia de conexões que espalham informações, dão voz às pessoas, constroem valores diferentes e dão acesso a esse tipo de valor [capital social]".

Para Tomaél; Alcará e Di Chiara (2005), a existência de redes sociais na Internet é possibilitada pela existência de um software social de interface amigável, que agrega recursos não específicos da tecnologia da informação. Via utilização desses recursos forma-se uma rede em que seus integrantes convidam outras pessoas de seu relacionamento pessoal e profissional para dela fazer parte. Enfim, são ambientes que proporcionam a formação de grupos de interesses que interagem por meio de relacionamentos comuns.

Referindo-se a software social, Recuero (2004, p. 7) observa que trata-se de "sistemas que visam proporcionar conexões entre as pessoas, gerando novos grupos e comunidades, simulando uma organização social".

Rheingold (1996) considera que grupos de pessoas que se formam para discutir assuntos de toda ordem ou transferir informações de interesses afins, através do uso de computadores integrantes de uma rede, constituem as comunidades virtuais.

Nesse tipo de rede de comunicação, mediada por computador, pessoas que dela participam podem formar agregados sociais, originados de debates de elevado número de participantes que comungam interesses e sentimentos, formando "teias de relações pessoais no ciberespaço", que é definido por Rheingold, como um espaço conceitual "onde manifestam palavras, relações humanas, dados, riqueza e poder dos utilizadores da tecnologia de CMC".

As comunidades virtuais são abrigadas pelas redes sociais virtuais, espaços criados no ciberespaço a partir de um contato repetido entre os indivíduos em um local simbólico delimitado por um tópico de interesse comum (PRIMO, 1997).

\section{Metodologia}

A metodologia adotada constituiu-se, resumidamente, nos seguintes procedimentos: 
1) pesquisa bibliográfica, levantamento e estudo das obras pertinentes ao estudo em questão;

2) levantamento do material empírico, seleção do tópico, assim como coleta dos dados para análise preliminar das informações ali registradas; e

3) análise das informações registradas, categorização das informações postadas, em estudo quantitativo por incidência, e avaliação qualitativa, considerando-se o seu conteúdo.

\section{5 "E o Rio?": apresentando o objeto de estudo}

Conforme resultados obtidos em pesquisa realizada no site Orkut, buscando por comunidades virtuais com o termo "sustentabilidade"13, constatou-se a existência de 82 comunidades.

Refinando a pesquisa para "sustentabilidade ambiental"14, obteve-se sete comunidades dedicadas ao tema. Os resultados de outras pesquisas feitas sobre comunidades virtuais sob os termos "ecologia" (388), "preservação ambiental" (28), "meio ambiente" (mais de mil) e "aquecimento global" (mais de mil), por exemplo, indicam a existência de vários fóruns brasileiros, no Orkut, preocupados com a sustentabilidade ambiental.

Desse modo, a numerosa presença de fóruns no Orkut, promovendo o debate da sustentabilidade ambiental - problemática tão relevante na contemporaneidade - indica a existência, também, de discussões de cunho sócio-político entre a massa jovem ${ }^{15}$ que prevalece no Orkut, e entre a aparente predominância da troca de recados e publicação de fotos no site.

Delimitou-se como objeto de estudo desta pesquisa o tópico "E o rio?", motivados por outras pesquisas em andamento, realizadas no contexto da cidade de Ferros, abordando o comportamento informacional dos seus habitantes, por um dos autores deste trabalho. Outra razão deveu-se ao corpo da comunidade (2.114 membros, sendo 28 destes enquanto debatedores no tópico em análise) e o número de mensagens no citado tópico (167) que se adequaram aos limites de tempo e de redação, característicos da natureza preliminar de um estudo exploratório.

O tópico "E o rio?" iniciado na citada comunidade virtual "Ferros MG", foi criado em 31 de maio de 2004. "Ferros MG" representa virtualmente a comunidade física de moradores e ex-moradores da cidade de Ferros, localizada na região central do Estado de Minas Gerais, com bacia hidrográfica pertencente à Bacia Rio Doce, que tem o Rio Santo

\footnotetext{
${ }^{13}$ Disponível em:

<http://www.orkut.com.br/Main\#UniversalSearch.aspx?pno=1\&searchFor=C\&q=sustentabilidade>. Acesso em: 26 out. 2009.

${ }^{14}$ Disponível em:

<http://www.orkut.com/Main\#UniversalSearch.aspx?pno=1\&searchFor=C\&q=sustentabilidade+ambiental>. Acesso em: 26 out. 2009.

${ }^{15}$ Segundo dados do senso demográfico do próprio Orkut, 54,49\% dos membros do Orkut tem entre 18 e 25 anos (Disponível em: <http://www.orkut.com.br/Main\#MembersAll.aspx>. Acesso em: 26 out. 2009.
} 
Antônio em discussão no tópico como principal afluente ${ }^{16}$. Segundo o IBGE $^{17}$, o município de Ferros tem mais de 11.200 habitantes e a divisão da população ocupada por setores econômicos mostra que a principal fonte de trabalho na cidade é o setor "agropecuário, extração vegetal e pesca".

Tendo como principais rios o Rio Santo Antônio e o Rio do Tanque, justifica-se a discussão sobre o futuro do Rio Santo Antônio, por meio do tópico "E o rio?", devido à importância do citado rio para Ferros e distritos.

\section{Apresentação e discussão dos resultados obtidos}

O debate promovido pelo tópico "E o rio?" foi iniciado em 31 de outubro de 2006, por Thays Silveira ${ }^{18}$ - ex-moradora de Ferros, segundo informações postadas no próprio fórum - com a seguinte mensagem:

Pessoal,

Tem alguém sabendo a respeito da audiência pública que aprovou a construção de uma usina hidrelétrica no Rio Santo Antônio, pouco acima de Ferros? Queria saber detalhes sobre isso. Fiquei preocupada...

Até a data do levantamento de dados desta pesquisa, 17 de março de 2009, o debate teve ao todo 167 mensagens, postadas por 28 membros da comunidade debatedora (54\% homens e $46 \%$ mulheres), entre a data de início da discussão e o dia 06 de março de 2009, data da última postagem. Em relação ao posicionamento diante da discussão principal, $75 \%$ dos membros declaram-se contra a instalação das PCHs na bacia do Rio Santo Antônio, $18 \%$ são favoráveis e $7 \%$ não expressam opinião clara ou estão indefinidos.

Nota-se que o tópico representa a insatisfação dos debatedores com a falta de fornecimento de informações claras por parte das autoridades envolvidas diretamente na instalação das PCHs, principalmente pela restrição das informações de interesse coletivo apenas ao contexto de lideranças políticas locais e externas, detentoras da tomada de decisões.

Percebe-se, também, insatisfação de debatedores com a empresa GlobalBank Consulting, responsável pelas obras das $\mathrm{PCHs}$, a partir da postagem de um dos membros, informando aos demais sobre a empreendedora responsável pelo projeto. Entre outras fontes de informação citadas no tópico, registra-se discussão sobre matéria do

\footnotetext{
${ }^{16}$ Segundo o Instituto de Geociências Aplicadas (IGA) e o IBGE. Disponível em:

<http://www.almg.gov.br/index.asp?grupo=estado\&diretorio=munmg\&arquivo=municipios\&municipio $=25903>$ . Acesso em: 26 out. 2009.

${ }^{17}$ Disponível em:

<http://www.almg.gov.br/index.asp?grupo=estado\&diretorio=munmg\&arquivo=municipios\&municipio=25903> . Acesso em: 26 out. 2009.

${ }^{18}$ Disponível em: <http://www.orkut.com.br/Main\#Profile.aspx?uid=11494210109571588727>. Acesso em 17 mar. 2009.
} 
jornal Estado de Minas ${ }^{19}$, que destaca as $\mathrm{PCH}$ como um negócio que envolve pelo menos 100 milhões de reais. Ao tomar conhecimento desta referida matéria, alguns membros manifestaram-se desconfiados da real motivação para a instalação das PCHs, sugerindo prevalecerem interesses econômicos em detrimento de impactos ambientais.

A Tabela 1 apresenta a categorização atribuída às mensagens postadas em "E o rio?". Sugere-se a existência de uma lacuna informacional, situação problemática em que surge um vazio de informações incapaz de responder aos anseios de um indivíduo, sendo que a busca por informação objetiva preencher tal vazio (BELKIIN, 1980 apud GONZÁLEZ DE GÓMEZ, 1990, p. 120).

Tabela 1 - Conteúdos constantes nas informações registradas no tópico "E o Rio?" - 2009

\begin{tabular}{|c|c|c|}
\hline CONTEÚDOS & $f$ & $\%$ \\
\hline Pedidos de informações sobre as hidrelétricas & 15 & 9,0 \\
\hline Pedidos de transparência nas ações políticas do governo estadual & 14 & 8,3 \\
\hline $\begin{array}{l}\text { Informações políticas e legais pertinentes à permissão e/ou } \\
\text { proibição das obras para as } \mathrm{PCHs}\end{array}$ & 14 & 8,3 \\
\hline Esclarecimentos sobre preservação da fauna e flora local & 18 & 11,0 \\
\hline $\begin{array}{l}\text { Indicação de ONGS ambientalistas, líderes locais, pesquisadores } \\
\text { e especialistas em sustentabilidade ambiental como fontes para } \\
\text { informações mais precisas }\end{array}$ & 11 & 6,5 \\
\hline $\begin{array}{l}\text { Indicação de matérias jornalísticas sobre as PCHs e/ou } \\
\text { sustentabilidade ambiental }\end{array}$ & 13 & 7,8 \\
\hline Retornos de contatos com as fontes indicadas no tópico & 9 & 5,4 \\
\hline Exposição de aspectos positivos das PCHs/ contrapontos & 13 & 7,8 \\
\hline Manifestações de impotência para solucionar a questão & 28 & 16,8 \\
\hline Ironias ao governo/ humor & 16 & 9,5 \\
\hline Comentários de apoio à discussão & 13 & 7,8 \\
\hline $\begin{array}{l}\text { Poema sobre sustentabilidade ambiental de autoria de moradora } \\
\text { da cidade }\end{array}$ & 1 & 0,6 \\
\hline Mensagens não relacionadas à discussão & 2 & 1,2 \\
\hline Total & 167 & $100 \%$ \\
\hline
\end{tabular}

Fonte: "E o rio?" disponível em:

http://www.orkut.com.br/Main\#CommTopics.aspx?cmm=78051

\footnotetext{
${ }^{19}$ Disponível em:

<http://www.uai.com.br/UAI/html/sessao_2/2008/08/04/em_noticia_interna,id_sessao=2\&id_noticia=74229/e m_noticia_interna.shtml>. Acesso em: 26 out. 2009.
} 
Com isso, a análise desses dados nos aponta um comportamento informacional dos debatedores do tópico como predominantemente de busca e troca de informações satisfatórias a respeito das $\mathrm{PCHs}$, por meio da constatação de que $56,3 \%$ das mensagens têm esse perfil, considerando as sete primeiras categorizações das mensagens (Tabela 1, f. 7). Além disso, $16,8 \%$ dos comentários postados são depoimentos de impotência perante a situação do rio e às informações disponíveis e 9,5\% ironias ao governo e seus órgãos ambientais, demonstrando descrença em relação às informações oficiais.

Tal visão de desconfiança quanto à credibilidade de determinadas fontes, também pode ser percebida ao verificar que, dentre as 41 fontes citadas para obtenção e/ou questionamento de informações sobre a sustentabilidade ambiental e a instalação das PCHs no município de Ferros $^{20}$, em todas as citações feitas às fontes governamentais e/ou ligadas diretamente ao projeto das hidrelétricas, parecem ser referenciadas como não confiáveis, incompletas e/ou responsáveis pelo descaso com a sustentabilidade ambiental, ao passo que todas as fontes ligadas a ONGS e pesquisadores ambientais não atrelados diretamente ao projeto das PCHs são apontadas como verídicas, compromissadas com a sustentabilidade ambiental, e possíveis fomentadoras de soluções para o problema.

Antes de analisarmos, sinteticamente, a qualidade e o conteúdo das informações postadas pelos membros no tópico em estudo, é importante citar um debate entre o progresso gerado pelo desenvolvimento tecnológico e o desenvolvimento sustentável, em que Paulo Lessa ${ }^{21}$, favorável à instalação das PCHs em Ferros, faz uma analogia defendendo seu ponto de vista: "Não se faz um omelete sem quebrar os ovos. Voces (sic) estão olhando apenas pra casca do ovo, sem considerar o omelete. Então, ao invés disto, deveriam olhar o todo", para ter como uma das

${ }^{20}$ (1) GlobalBank - empreendedora responsável pelo projeto; (2) FEAM - Fundação Estadual do Meio Ambiente; (3) Cemig; (4) Governo do Estado; (5) GESTA - Grupo de Estudos sobre Temática Ambiental (FAFICH - UFMG); (6) ONG Coalizão Rios Vivos; (7) ADDAF - Associação de Desenvolvimento e Defesa do Meio Ambiente em Ferros; (8) CBH - Comitê da Bacia Hidrográfica do Rio Santo Antônio; (9) Projeto Manuelzão da UFMG; (10) Green Peace; (11) Daniela Chaves Resende - pesquisadora de impacto ambiental do levantamento da GlobalBank; (12) Anderson Latini - pesquisador de impacto ambiental do levantamento da GlobalBank; (13) COPAM - Conselho Estadual de Política Ambiental; (14) Prefeitura de Ferros; (15) MMX - empreendedora da construção de mineriodutos na região; (16) FIEMG - Federação das Indústrias de Minas Gerais; (17) International Rives - ONG internacional de defesa aos rios; (18) Igam - Instituto Mineiro de Gestão das Águas; (19) SEMAD - Secretaria de Estado de Meio-Ambiente e Desenvolvimento Sustentável em MG; (20) Tininha ADDAF; (21) Galvam construtora Ltda - construtora envolvida no projeto das PCHs; (22) MAB- movimento de atingidos por barragens; (23) Dr. Leonardo - advogado representante da MAB; (24) Dra. Rogéria representante do $\mathrm{CBH}$; (25) Dr. Rodrigo, advogado contratado pela ADDAF; (26) ANEEL- Agência Nacional de energia elétrica; (27) Prof. Jorge Dergam da Universidade Federal de Viçosa - pesquisador do risco de extinção de peixes na Bacia do Rio Doce, incluindo o peixe Andirá, no Rio Santo Antônio; (28) Dr. Fábio Vieira, biólogo pesquisador da UFMG - pesquisa sobre a extinção de peixes no Rio Santo Antônio; (29) Elza Gomes da Silveira - poema (moradora da comunidade); (30) Ministério Público; (31) Luiz Antonio Barros da Silva - engenheiro agrônomo da DELPHI Projetos e Gestão Ltda - contratada pela Peixe Energia S.A (GlobalBank) para estudo da área; (32) Suprams - Superintendências Regionais de Minas Gerais; (33) Policia Militar do Meio Ambiente de Ferros; (34) IEF - Instituto Estadual de Florestas; Copaer (sic) - Corpaer (Batalhão de Radiopatrulhamento Aéreo) da PM-MG que atua em parceria com a Semad em patrulhamentos ambientais; (35) Cobom - Central de Operação Bombeiro Militares; (36) Câmara de vereadores de Ferros MG; (37) Jornal Correio Brasiliense; (38) Estado de Minas; (39) Portal UAI; (40) EIA - Estudo de Impacto Ambiental à região; (41) RIMA - Relatório de Estudo de Impacto Ambiental.

${ }^{21}$ Disponível em: <http://www.orkut.com.br/Main\#Profile.aspx?uid=2449127758096757160>. Acesso em: 17 mar. 2009. 
respostas a mensagem de Cyro Gonçalves"22: "não se trata de fazer omelete. A questão é bem mais séria. [...] Se você está interessado mesmo na questão [...] dê uma lida nos projetos [...] Procure se informar antes de ter opinião".

O diálogo, assim como outros no tópico, demonstra o valor dado pelos participantes à informação como: ferramenta de conscientização política e social; instrumento de convencimento (um dos membros do debate, Nerynho ${ }^{23}$, inicialmente contra as $\mathrm{PCHs}$, mudou de opinião após ler os argumentos dados pelos debatedores favoráveis); e direito básico da população.

Ao avaliarmos as mensagens postadas no tópico em estudo, percebemos como se expressam os pedidos de acesso à informação, transparência política e também a impotência perante a situação. 0 membro Cyro diz que "cheguei a uma única conclusão: é obscuro [...] Tem que ter informação e isto está faltando"; Thays, criadora do tópico, declara durante a discussão "alguém tem alguma informação clara sobre essa obra? [...] Isso é preocupante, e é sobre isso que estamos falando [...]"; e Henrique ${ }^{24}$ afirma que "a sociedade civil precisa exigir respostas transparentes".

Alguns dos membros chegam a definir cada participante como agente divulgador, valorizando o papel da informação como promovedora de mudanças e a necessidade de ter acesso a ela: "já estamos fazendo algo quando informamos aos participantes da comunidade o que está acontecendo. Infelizmente, como civis, é uma das poucas coisas que podemos fazer", diz, no tópico, uma das mensagens da organizadora do debate virtual (Thays).

A última mensagem postada em "E o rio?", por ocasião da coleta de dados para esta pesquisa, de autoria da presidente da ONG ADDAF, Tininha ${ }^{25}$, convida os debatedores a lerem os relatórios do projeto das PCHs, mobilizarem-se para a próxima audiência pública (não é divulgada a data) e participarem do abaixo assinado contra a hidrelétrica.

\section{Considerações finais}

Pelos resultados alcançados, conclui-se que o principal, para os debatedores mais atuantes assim como para a maioria dos membros do tópico sob análise, refere-se ao valor da informação enquanto sinônimo de exercício efetivo da cidadania; a importância da circulação e disseminação da informação entre os próprios membros da comunidade física e virtual e da comunidade externa; e a transparência da informação por parte dos detentores do poder de decisão, que devem garantir acesso pleno às informações de interesse e de direito público. Todos esses elementos indicam que a informação é percebida como determinante para a

\footnotetext{
${ }^{22}$ Disponível em: <http://www.orkut.com.br/Main\#Profile.aspx?uid=255470561797417366>. Acesso em: 17 mar. 2009.

${ }^{23}$ Disponível em: <http://www.orkut.com.br/Main\#Profile.aspx?uid=15030157239797955425>. Acesso em: 17 mar. 2009.

${ }^{24}$ Disponível em: <http://www.orkut.com.br/Main\#Profile.aspx?uid=15992842039646194307>. Acesso em: 17 mar. 2009.

${ }^{25}$ Disponível em: <http://www.orkut.com.br/Main\#Profile.aspx?uid=8292168955320277102>. Acesso em: 17 mar. 2009.
} 
sustentabilidade ambiental em Ferros - MG, pelos debatedores do tópico avaliado.

O estudo exploratório do comportamento informacional de um público não especializado, participante de uma rede virtual com conteúdos e culturas diversas, como o Orkut, constatou o nascimento espontâneo e consciente de um debate de relevância, como o da sustentabilidade ambiental.

Considerando as limitações naturais de um único trabalho esgotar todas as abordagens de análise possíveis, espera-se que este sirva de estímulo a outros estudos em Ciência da Informação, que se atentem à existência, comprovada por este estudo, de outros tipos de informações circulantes no Orkut, assim como avaliar o comportamento informacional de usuários de outros sites de relacionamento, que, além das mais aparentes e óbvias trocas de mensagens cotidianas, funcionam como repositórios de informações das mais diversas modalidades.

\section{Referências}

Assessoria Google. Dados sobre o Orkut. (Mensagem recebida por <ruleandson@gmail.com> em 12 set. 2008).

BELKIN, N. J. Anomalous states of knowledge as a basis for information retrieval. The Canadian Journal of Information Science, v. 5, p. 133 -143, May 1980.

DAVENPORT, T. H. Ecologia da informação: porque só a tecnologia não basta para o sucesso na era da informação. São Paulo: Futura, 1998. 316 p.

MINAS GERAIS. Assembleia Legislativa. Municípios mineiros: Ferros. Disponível

em:

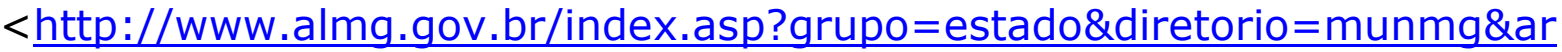
quivo=municipios\&municipio=25903 > Acesso em: 03 mar. de 2009. FRAGA, R. ComScore: Orkut lidera redes sociais no Brasil. Discovery, 15 set. 2011.

Disponível em: <http://googlediscovery.com/2011/09/15/comscore-orkut-lidera-asredes-sociais-no-brasil/> Acesso em: 24 mar. 2012.

FURTADO, B. Projeto de construção de usinas ameaça o Rio Santo Antônio. Estado de Minas, Belo Horizonte, 04 ago. 2008. Disponível em: <http://www.uai.com.br/UAI/html/sessao 2/2008/08/04/em noticia inte rna, id sessao $=2 \& i d$ noticia $=74229 /$ em noticia interna.shtml $>$. Acesso em: 30 mar. 2009.

GARTON, Laura; HAYTHORNTHWAITE, Caroline; WELLMAN, Barry. Studying online social networks. Journal of Computer-Mediated Communication, v. 3, n. 1, 1997. Disponível em: $<$ http://jcmc.indiana.edu/vol3/issue1/garton.htmI\#References $>$. Acesso em: 26 mar. 2011.

GONZÁlEZ DE GOMEZ, M. N. O objeto de estudo da Ciência da Informação: paradoxos e desafios. Ciência da Informação, Brasília, v. 19, n. 2, p. 117-22, jul./dez. 1990. Disponível em: 
$<$ http://revista.ibict.br/cienciadainformacao/index.php/ciinf/article/view/1 376>.

Acesso em: 30 ago. 2009.

IBOPE. Brasil superou o número de 40 milhões de pessoas com acesso à Internet. Disponível em: $<$ http://www.ibope.com.br/calandraWeb/servlet/CalandraRedirect?temp= $6 \&$ proj=PortalIBOPE\&pub $=T \& d b=c a l d b \& c o m p=$ pesquisa leitura\&nivel=nul I\&docid=F0BA65FF8A513A48832574750050527E>. Acesso em: 30 ago. 2009.

JACOBI, P. Sustentabilidade ambiental, consumo e cidadania. Ambiente e Sociedade, Campinas, v. 9, n. 1, p. 183-186, jan./jun. 2006. Disponível em: $\quad<$ http://www.scielo.br/scielo.php?script=sci arttext\&pid=S1414753X2006000100010\&lng=en\&nrm=iso >. Acesso em: 26 mar. 2010.

JOHNSON, M. O Orkut está fazendo 5 anos!. Disponível em: $<$ http://blog.orkut.com/2009/01/orkut-is-turning-five.html>. Acesso em: 03 mar. 2009.

MACEDO, T. M. B. Redes informais nas organizações: a co-gestão do conhecimento. Ciência da Informação, Brasília, v. 28, n. 1, p. 94 - 100, jan. $1999 . \quad$ Disponível em: <http://revista.ibict.br/index.php/ciinf/article/view/332>.

Acesso em: 24 mar. 2010.

MAGLIO, I. C. A sustentabilidade ambiental no planejamento urbano do Município de São Paulo. 421 f. 2005. Tese (Doutorado em Saúde Pública) - Faculdade de Saúde Pública da Usp, FSP/USP, São Paulo, 2005. Disponível em: <http://www.teses.usp.br/teses/disponiveis/6/6134/tde05062008-160111/>. Acesso em: 10 mar. 2009.

MARTINS, R. Site é o mais acessado do Brasil, sem sinais de queda. Acesso

em:

$<$ http://br.tecnologia.yahoo.com/article/30012008/25/tecnologia-noticiassite-acessado-brasil-sinais-queda.html>. Acesso em: 3 mar. 2009.

MARTELETO, R. M. Informação e sociedade: novos parâmetros teóricopráticos de gestão e transferência informacional. São Paulo em Perspectiva, Campinas, v. 12, n. 4, p. 78-82, out./dez. 1998. Disponível em:

$<$ http://www.seade.gov.br/produtos/spp/index.php?men=rev\&cod=2098 Acesso em: 25 mar. 2010.

MARTELETO, R. M.; SILVA, A. B. de O. e. Redes e capital social: o enfoque da informação para o desenvolvimento local. Ciência da Informação, Brasília, v. 33, n. 3, p. 41-49, set./dez. 2004. Disponível em: Disponível em: http://revista.ibict.br/ciinf/index.php/ciinf/article/view/518/472 . Acesso em: 06 maio 2012.

MUNIZ, D. Internauta brasileiro fica 3 vezes mais no Orkut do que no email. Folha de São Paulo, São Paulo, 19 dez. 2007. Disponível em: <http://www1.folha.uol.com.br/folha/informatica/ult124u356362.shtml >. Acesso em: 30 ago. 2008.

PORTILHO, F. Sustentabilidade ambiental, consumo e cidadania. São Paulo: Cortez, 2005. 255 p. Recensão de JACOBI, P. Ambiente \& 
Sociedade, Campinas, v. 9, n. 1, jan./jun. 2006. Disponível em: $<$ http://www.scielo.br/scielo.php?pid=S1414-

753X2006000100010\&script=sci arttext> Acesso em: 5 abr. 2009.

PRIMO, A. F. T. A emergência das comunidades virtuais. In: CONGRESSO DA INTERCOM, 20., 1997, Santos. Anais... Santos: INTERCOM, 1997. Disponível em: $<$ http://usr.psico.ufrgs.br/ aprimo/pb/comuni.htm>. Acesso em: 30 ago. 2008.

RECUERO, R. da C. Comunidades virtuais: uma abordagem teórica, 2008. Disponível em: < http://pontomidia.com.br/raquel/teorica.htm $>$. Acesso em: 03 mar. 2009.

Dinâmicas de redes sociais no Orkut e capital social. 2006. Disponível em: $<$ http://pontomidia.com.br/raquel/alaic2006.pdf >. Acesso em: 03 mar. 2009.

Futures of learning: o Orkut e o Brasil, 2009. Disponível em: <http://pontomidia.com.br/raquel/arquivos/futures_of_learning_o_orkut_ e_o_brasil.html> Acesso em: 20 mar. 2009.

- Redes sociais. In: SPYER, J. (Org.). Para entender a Internet: noções, práticas e desafios da comunicação em rede. Não Zero, 2009.

Redes sociais na Internet: considerações iniciais. In: ENCONTRO DOS NÚCLEOS DE PESQUISA DA XXVII INTERCOM, 4., Porto Alegre, RS, 2004. Anais... Porto Alegre: INTERCOM, 2004. Disponível em: $<$ http://www.bocc.ubi.pt/pag/recuero-raquel-redes-sociais-na-

internet.pdf>. Acesso em: 10 out. 2009.

RHEINGOLD, H. A comunidade virtual. Lisboa: Gradiva, 1996. 367 p.

TEMPO gasto por brasileiros na Internet chega a 24 horas mensais. 0 Globo, Rio de Janeiro, 24 abr. 2008. Disponível em: <http://oglobo.globo.com/tecnologia/mat/2008/04/24/tempo gasto por brasileiros na internet chega 24 horas mensais-427036168.asp $>$.

Acesso em: 30 abr. 2008.

TOMAÉL, M. I.; ALCARÁ, A. R.; DI CHIARA, I. G. Das redes sociais à inovação. Ciência da Informação, Brasília, v. 34, n. 2, p. 93-104, 2005. Disponível em: <http://revista.ibict.br/ciinf/index.php/ciinf/article/view/642>. Acesso em: 10 maio 2012.

TOTAL de pessoas com acesso à Internet atinge 77,8 milhões. Disponível em:

$<$ http://www.ibope.com.br/calandraWeb/servlet/CalandraRedirect?tem $\mathrm{p}=5 \& p r o j=$ PortalIBOPE $\& \mathrm{pub}=\mathrm{T} \& \mathrm{db}=\mathrm{caldb} \& \mathrm{comp}=$ Noticias\&docid $=\mathrm{C} 2 \mathrm{~A} 2$ CAE41B62E75E83257907000EC04F>. Acesso em: 26 mar. 2011. 